\title{
Atuação do observatório social no município de Santa Maria \RS
}

\author{
Kelin Medianeira Hoffmann ${ }^{1}$ \\ Bruna Faccin Camargo ${ }^{2}$ \\ Jocias Maier Zanatta
}

Resumo: O presente artigo objetivou analisar as contribuições do 'Observatório Social' do Município de Santa Maria (RS) com viés no controle social da administração pública, assim como a percepção da importância que o observatório tem como protagonista para o monitoramento dos gastos públicos e participação nas ações e decisões do ente público. O estudo observou a maneira e a forma de atuação do 'Observatório Social' junto ao município, e também relacionou e demonstrou como a participação da sociedade no controle social pode contribuir na aplicação e na transparência da alocação dos recursos públicos. Para tanto, adotou-se como procedimentos metodológicos a utilização da pesquisa explicativa, descritiva e análise documental com abordagem qualitativa. A pesquisa constatou que as contribuições do observatório social na gestão pública do munícipio estão focadas na transparência dos processos, redução de custos, prevenção de irregularidades das licitações, palestras de educação fiscal e promoção da cidadania. Os resultados apontam que o trabalho desenvolvido no período de janeiro a agosto de 2019 pelo observatório, em parceria com a Prefeitura, gerou uma economia aproximada de $\mathrm{R} \$ 323.300,00$ no período, e tal constatação serve de alerta para os gestores públicos e para a sociedade em geral e demonstra a necessidade da existência do observatório nas várias esferas governamentais.

Palavras-chave: Gestão Pública, Controle Social, Observatório Social.

\section{Performance of the social observatory in the municipality of Santa Maria $\backslash$ RS}

\begin{abstract}
This article aimed to analyze the contributions of the 'Social Observatory' of the Municipality of Santa Maria (RS) with a bias in the social control of public administration, as well as the perception of the importance of the observatory as a protagonist in monitoring public spending and participation in actions and decisions of the public entity. The study observed the manner and form of action of the 'Social Observatory' with the municipality, and also related and demonstrated how society's participation in social control can contribute to the application and transparency of the allocation of public resources. Therefore, it adopted as methodological procedures using the explanatory, descriptive document analysis and qualitative approach. The research found that the contributions of the social observatory in the municipality's public management are focused on the transparency of processes, cost reduction, prevention of irregularities in bidding, lectures on tax education and promotion of citizenship. The results show that the work carried out from January to August 2019 by the observatory, in partnership with the City Hall, generated an approximate saving of $\mathrm{R} \$ 323,300.00$ in the period, and this finding serves as a warning to public managers and to the society and demonstrates the need for the existence of the observatory in the various spheres of government.
\end{abstract}

Keywords: Public Management, Social Control, Social Observatory.

\footnotetext{
${ }^{1}$ Pós Graduada em Auditoria e Controladoria (UFN). E-mail: kelin.hoffmann@gmail.com.

2 Mestre em Desenvolvimento (UNIJUI), Doutoranda em Contabilidade e Finanças (UNIZAR). Docente na Universidade Franciscana (UFN). E-mail: brunafaccinflor@hotmail.com. Docente da Universidade Franciscana (UFN).

3 Mestre em Desenvolvimento (UNIJIU). Doutorando em Administração (UFSM). E-mail: josk85@gmail.com.
} 


\section{Introdução}

O acompanhamento dos recursos financeiros públicos realizados por uma sociedade participativa e consciente da atuação dos seus representantes políticos, permite o exercício da democracia e da cidadania de maneira mais ampla, quando todo cidadão possui o livre arbítrio de opinar e fiscalizar os gastos públicos. Esta supervisão pode prevenir e combater os desvios em prol de interesses individuais dos governantes, prejudicando o bem-estar coletivo da sociedade e o crescimento e desenvolvimento do país (FIGUEIREDO; SANTOS, 2013).

A Constituição Federal do Brasil, predispondo a prevalência do controle social sobre a Administração Pública, menciona a importância da participação da sociedade civil na fiscalização e no controle da maneira como ocorre a utilização do recurso financeiro público, bem como na identificação de onde tem sido aplicado o recurso ou como os agentes públicos têm executado o trabalho (BRASIL, 1988).

Segundo Queiroz (2017), os princípios da administração pública apontam que a sociedade tem o dever de fiscalizar e acompanhar e até mesmo controlar o que é feito pelos governantes. Para que funcione de maneira efetiva e correta, os observatórios sociais desempenham esta função, de forma sistematizada e eficaz, atuam no fluxo do processo, em tempo real, monitorando as ações do gestor público e se estão de acordo com as diretrizes.

O relacionamento da sociedade com uma administração pública transparente consiste na participação do cidadão na gestão e no controle da administração pública e, "para que essa expectativa se torne realidade, é essencial que o cidadão tenha capacidade de conhecer e compreender as informações divulgadas" (FIGUEIREDO; SANTOS, 2013, p.2).

O controle exercido pelos cidadãos perante o poder público constitui um bem público fundamental à constituição de uma sociedade justa e democrática. Ao analisar os novos movimentos sociais brasileiros, Gohn (2010) considera a habilidade destes em intervir e construir a esfera pública como um dos grandes saldos nos últimos vinte anos, em que o foco esteve na redemocratização do país.

A participação social consiste, portanto, "em canais institucionais de participação na gestão governamental, com a presença de novos sujeitos coletivos nos processos decisórios, não se confundindo com os movimentos sociais que permanecem autônomos em relação ao Estado" (ASSIS; VILLA, 2003, p. 377).

O enfoque principal desta pesquisa foi observar as estratégias e as contribuições que a sociedade civil pode promover por meio da participação voluntária no observatório social do município santa-mariense, ao monitorar e fiscalizar sistematicamente as ações do Poder Público, auxiliando assim na boa gestão pública ao município. 
O Observatório Social (OS) é um espaço para o exercício da cidadania, sendo uma instituição não governamental, sem fins lucrativos, regido por estatuto, além de outras disposições legais aplicáveis. Deve ser composto por cidadãos brasileiros apartidários, que transformam o direito de indignar em atitude, com ações práticas de exercício de cidadania e controle social, em favor da transparência e da qualidade na aplicação dos recursos públicos, com o objetivo de contribuir para a melhoria da gestão pública.

Tendo em vista a temática abordada, apresenta-se a seguinte questão de pesquisa: de qual maneira o 'Observatório Social' do Munícipio de Santa Maria, no Estado do Rio Grande do Sul, pode contribuir para o exercício do controle social da gestão pública municipal?

O objetivo geral da pesquisa foi analisar as contribuições do OS do Município para o exercício do controle social da administração pública, por meio da descrição da composição, atuação e estrutura do observatório, com apresentação posterior dos resultados obtidos com a intervenção junto ao município. Além desse, almejou-se observar e descrever a forma de atuação do OSSM, demonstrando a contribuição do controle social na aplicação e na transparência da alocação dos recursos públicos.

Por tratar-se de um assunto de relevância social, há evidência acerca da importância da ação do cidadão voluntário no observatório, por intermédio do controle social, de modo que incorra em melhoria da administração pública como resultado do monitoramento das ações dos governantes do munícipio, cujo processo transcorre também a partir das licitações ou das ações de educação fiscal com a sociedade.

Com tal intento, a pesquisa apresenta relevância gregária, porquanto se propõe a realizar e contribuir para uma análise das práticas aplicadas, principalmente, no que se refere a potencializar o envolvimento dos membros voluntários da sociedade civil, no pleito das discussões da gestão pública.

\section{Referencial Teórico}

\section{Observatório Social no Brasil}

O primeiro Observatório Social foi constituído no ano de 2005 no Estado de Paraná, tendo como missão despertar o espírito de Cidadania Fiscal na sociedade organizada, tornando-a proativa, tendo em vista que com o OS, a sociedade poderá exercer a vigilância social na administração pública (OSB, 2019). Em suma síntese, o observatório é constituído para o exercício da cidadania, alicerçado em bases democráticas e apartidárias ao reunir o maior número possível de entidades representativas da sociedade civil, com o objetivo de melhoria da gestão pública (OSB, 2019). 
O principal objetivo do observatório é contribuir para a transparência na gestão pública, fomentar o controle social dos gastos públicos, a educação fiscal, e incentivar a participação de micro e pequenas empresas do munícipio, promovendo melhor qualidade e preços nas compras públicas, ou seja, aumentando a concorrência nas licitações, contribuindo, assim, para diminuição da confecção do preço, tanto dos serviços, como dos produtos licitados. Desta forma, incentivar os pequenos empresários em participar das licitações, por meio da democratização das compras públicas e incentivando o empreendedorismo e o emprego no munícipio é missão do OS (OSB, 2019).

O Quadro 1 apresenta o detalhamento da forma de atuação do Observatório Social do Brasil - OSB, com a finalidade do propiciar a ampliação do entendimento sobre o trabalho realizado pela entidade social. Vejamos:

Quadro 1 - Detalhamento sobre a forma de atuação do OSB.

\begin{tabular}{|c|l|}
\hline $\begin{array}{c}\text { PRINCÍPIO } \\
\text { GERAL }\end{array}$ & $\begin{array}{l}\text { A justiça social será alcançada quando todos os agentes recolhem seus } \\
\text { tributos corretamente, os agentes públicos os aplicarem com ética e } \\
\text { eficácia. }\end{array}$ \\
\hline MISSÃO & $\begin{array}{l}\text { Despertar o espírito da Cidadania Fiscal na sociedade organizada, } \\
\text { tornando-a proativa, através do seu próprio Observatório Social, exercendo } \\
\text { a vigilância social na sua comunidade, integrando o Sistema Observatório } \\
\text { Social do Brasil. }\end{array}$ \\
\hline VISÃO & $\begin{array}{l}\text { Ser um sistema nacional propulsor do controle social para o } \\
\text { aprimoramento da gestão pública e integridade empresarial. }\end{array}$ \\
\hline VALORES & $\begin{array}{l}\text { Apartidarismo; cidadania; comprometimento com a justiça social; atitude } \\
\text { ética, técnica e proativa; ação preventiva e visão de longo prazo. }\end{array}$ \\
\hline OBJETIVO & $\begin{array}{l}\text { Fomentar e apoiar a consolidação do Sistema OSB de Controle Social, a } \\
\text { partir da padronização dos procedimentos de monitoramento e controle da } \\
\text { gestão pública, além da disseminação de ferramentas de educação fiscal e } \\
\text { de inserção das micro e pequena empresa no rol de fornecedores das } \\
\text { prefeituras municipais. }\end{array}$ \\
\hline OBJETO DE \\
ATUAÇÃO & $\begin{array}{l}\text { As ações de educação para a cidadania fiscal e controle social focadas no } \\
\text { presente serão objeto de atuação do OS, atuando preventivamente, em } \\
\text { tempo real, contribuindo para a eficiência da gestão pública, por meio da } \\
\text { vigilância social da execução orçamentaria, em sinergia com os órgãos } \\
\text { oficiais controladores. }\end{array}$ \\
\hline
\end{tabular}

Fonte: Adaptado do Portal Oficial do Observatório Social do Brasil (2019a)

Conforme disposto no Quadro 1, o Observatório Social é integrado por cidadãos brasileiros que atuam em favor da transparência e da qualidade na aplicação dos recursos públicos, tendo como missão despertar na sociedade a cidadania, ou seja, o exercício da vigilância social. Sua visão é ser um sistema propulsor do controle social, auxiliando a gestão pública; com 
relação aos valores, o OSB tem como comprometimento a justiça social, a ética e a visão preventiva dos atos da administração pública.

$\mathrm{Na}$ concepção de Figueiredo e Santos (2013), um dos pilares fundamentais da democracia é a efetiva participação da sociedade nos assuntos de seu interesse, de forma que quanto mais participativa for a sociedade no ente público, mais consolidada será a democracia. A transparência e o controle social devem ser conceitos inseparáveis dentro de uma administração pública, considerado como objetivo comum o bem-estar e o interesse coletivo.

É através da cidadania voluntária exercida por diversas áreas de profissionais, que esta diversidade de conhecimentos sintetiza o enriquecimento do sistema de operação de monitoramento das ações públicas, sejam eles, empresários, professores, estudantes, funcionários públicos e outros cidadãos que, voluntariamente, entregam-se à causa da justiça social, com um único objetivo: fomentar o controle social no ente público.

Para isso acontecer, é de suma importância que os voluntários envolvidos no trabalho do observatório não tenham vínculo partidário, pois a atuação de controle e de fiscalização exercida por este programa precisa ocorrer de maneira imparcial, não podendo haver integrante vinculado com organização político-partidárias, pois este poderia vir a ser omisso propositalmente (OSB, 2019).

A participação da sociedade civil organizada na administração pública contribui no desenvolvimento de uma atividade harmônica, com o viés de planejar um conjunto de procedimentos mais adequados para a construção de um Estado Democrático, construindo uma gestão eficiente para minimizar as necessidades da sociedade como assistência social, saúde, educação, segurança pública, saneamento básico, entre outras (ALVES, 2015).

Para se desenvolver um trabalho com ética e serenidade, as pessoas envolvidas deverão ser de diversas etnias e classes sociais, profissionais das mais diversas áreas, para proporcionar um ambiente democrático, rico em diversidades de conhecimentos, mas atento aos anseios da sociedade (OSB, 2019).

Atualmente, o OSB coordena uma rede de observatórios sociais em mais de 141 municípios, composto por 17 estados brasileiros, com o intuito de contribuição na transparência das contas públicas e no controle social dos gastos públicos. O OSB já contribuiu para uma economia de milhões de reais aos cofres públicos municipais, devido ao empenho e atuação dos voluntários, junto a várias prefeituras de todo o país (OSB, 2019).

De acordo com dados do OSB (2019a), os estados com maiores unidades de observatórios sociais são: Paraná que possui 32 munícipios, seguido por Santa Catarina com 28 OS, São Paulo com 22 OS e na quarta posição, o Rio Grande do Sul, que conta com 16 OS. No 
RS, os OS estão estabelecidos nas cidades de Bento Gonçalves, Cachoeirinha, Caxias do Sul, Cruz Alta, Erechim, Farroupilha, Gravataí, Glorinha, Guaíba, Lajeado, Novo Hamburgo, Pelotas, Porto Alegre, Santa Maria, Santa Rosa e São Leopoldo.

A coordenação de todas as unidades dos observatórios é efetuada pelo OSB, que dissemina o trabalho recorrendo a uma rede de atuação, a fim de assegurar a disseminação de uma metodologia padronizada para todos os observatórios de nível municipal, promovendo a capacitação dos observadores, o exercício da cidadania de forma democrática e ética, e oferecendo suporte técnico aos OSs.

A missão de cada observatório constituído visa permanentemente operar com ações de educação fiscal para a sociedade em geral e o auxílio no controle fiscal como objeto de atuação, e como forma de atuação, a prevenção em tempo real nos gastos públicos, contribuindo, desta maneira, na eficiência da gestão pública, por meio da vigilância social constante da execução orçamentária, em sinergia com o ente público (OSB, 2019).

Conforme descrito nos preceitos, verifica-se que o sistema de atuação possui valores bem delineados, que norteiam as diretrizes de atuação, dando ênfase à eficácia. Identificou-se que os observatórios são instituições independentes, cujo intuito é o de contribuir com o poder público, por intermédio da participação social da sociedade, com apresentação posterior dos trabalhos realizados.

\section{Controle social na Administração Pública}

O controle social exercido pelo cidadão comum na esfera pública, tem garantias constitucionais, no âmbito da democracia e cidadania, sendo um exercício de compartilhamento de poder e decisão entre Estado e sociedade, sobre as atuações do poder público (OSB, 2019). Tenório (2006) complementa que o termo "gestão social" está alicerçado na democracia e deve sobressair o coletivo em detrimento do individual. Já Avritzer (2008), analisa os diversos desenhos participativos em relação "a capacidade de aprofundar práticas democráticas e a capacidade de tornar o desenho efetivo na determinação da política pública em questão" (AVRITZER, 2008, p.60).

Conforme a Lei da Responsabilidade Fiscal (2000) o acompanhamento do cidadão na prestação de contas da administração pública é garantido por lei, sendo este um registro importante na história da administração pública, advindo do artigo 163 da Constituição Federal do Brasil de 1988, que normatiza as finanças públicas voltadas para a responsabilidade da gestão fiscal (BEHN, 1988). 
A constituição brasileira determina aos representantes públicos o respeito à soberania popular, porém é a participação da população que torna efetiva a democratização nas políticas públicas. Estudos anteriores (KLEBA; WENDAUSEN, 2009; MILANI, 2008; TENÓRIO, 2006) discutem a participação social e seus impactos, já Vieira (2008) apresenta os impactos positivos da participação social no aumento da transparência e na diminuição dos índices de desigualdade social, em consonância à previsão constitucional.

A Lei de Responsabilidade Fiscal na administração pública institui o controle dos atos dos responsáveis com a gestão pública e com os recursos financeiros na gestão fiscal, tendo como intenção garantir maior compromisso dos gestores nas ações de planejamento e também no melhoramento do controle da gestão com a sociedade (BEHN, 1988).

A Constituição de 1988 foi um marco ao incluir diversos instrumentos participativos no processo de redemocratização, que previu novos mecanismos de participação da sociedade no controle da administração pública, que vão desde os conselhos de políticas públicas, audiências públicas, projetos de lei de iniciativa popular, plebiscitos e até os referendos (DOIN, 2012).

Na concepção de Queiroz (2017), administração pública tem como principal viés o controle, que está diretamente ligado à posição do órgão controlador: seja ele externo, interno ou social. O controle externo é exercido pelo Tribunal de Contas e pelo Poder Legislativo, instâncias que atuam fora da estrutura controlada; já o segundo, é exercido internamente, dentro de cada entidade ou Poder Autônomo, realizado por unidades de controle interno; o controle social, não menos importante, é exercido pela sociedade civil, tendo como principal função a prospecção da justiça social, mediante provocação dos controles internos e externos na administração pública, no que tange à aplicabilidade dos recursos públicos.

De tal modo, a atuação ativa da sociedade na fiscalização e na participação da atividade administrativa do Estado, sendo no acompanhamento da aplicação dos recursos, na execução e na prestação de contas da gestão pública, possibilita que o cidadão exerça uma função primordial, tanto de monitoramento, como de averiguação, seja de forma direta ou indiretamente nos atos da administração pública, o que torna possível a detecção de possíveis fraudes, atos ilícitos ou vícios (SOUZA, 2018).

A ação dos observatórios sociais na administração pública proporciona à sociedade brasileira impactos promissores com a cidadania, o fortalecimento da democracia, com a redução de atos ilícitos pelos governantes, resultando na melhoria da qualidade de vida dos cidadãos, por meio da atuação dos voluntários conjuntamente nas políticas públicas, com projetos de educação fiscal com a população, aumento de quantidade de empresas na concorrência das licitações, possibilitando, assim, um aumento na ofertas de vagas de empregos à população (SILVA, 2017). 
Souza (2018) afirma que os observatórios sociais são eficazes em relação ao combate e à prevenção da corrupção na administração pública, uma vez que reúnem diversas pessoas de diversos setores da sociedade, que possuem múltiplos conhecimentos técnicos capazes de interpretar dados divulgados pela administração pública, que costuma publicizar os seus atos com a utilização de uma linguagem difícil de ser compreendida pelos cidadãos.

\section{Metodologia}

A pesquisa consistiu em um estudo de caso do observatório social do município de Santa Maria - RS, que teve o intuito de descrever e analisar a forma de atuação do referido OS na sociedade, especificamente na gestão do biênio de 2019/2020.

Para alcançar os objetivos propostos, utilizou-se como procedimentos metodológicos a pesquisa explicativa e descritiva, uma vez que se realizou um estudo com a finalidade de identificar e descrever fatos a partir das informações coletadas sobre o assunto. No entendimento de Cervo, Bervian e Silva (2007), a pesquisa descritiva tem por objetivo descrever as características do tema pesquisado, enquanto a explicativa procura conectar as ideias para compreender as causas e efeitos da pesquisa, uma vez que aprofunda o conhecimento da pesquisa.

Quanto à abordagem, a pesquisa é classificada como qualitativa, envolvendo análise e reflexão sobre as percepções para obter um entendimento das atividades sociais e humanas (COLLIS; HUSSEY, 2005), que se propôs a averiguar as formas de atuação e as contribuições que o observatório social do município desenvolve para o exercício do controle social e da cidadania.

Empregou-se também a pesquisa documental, com a utilização de matérias da instituição em estudo, o que permitiu ao pesquisador ampliar conhecimentos sobre o assunto estudado (Gil, 2017). Na concepção de Beuren (2008), a pesquisa documental é caracterizada pela notabilidade, em que se justifica e organiza as informações que se encontram dispersas, conferindo uma nova importância como fonte de consulta.

A pesquisa utilizou-se da coleta de dados no período da gestão administrativa (2019/2020) do Observatório Social do município de Santa Maria/RS, com coleta de dados do período de janeiro a agosto de 2019, não abrangendo outros períodos tendo em vista a ausência de documentos ou informações que comprovem a atuação junto ao município.

Os dados foram extraídos a partir de informações contidas no site institucional do OSB, materiais disponibilizados aos franqueados, e com contatos realizados de forma informal e técnica, assim como mediante a observação do participante, realizadas em capacitações com 
palestras e cursos. A concepção do estudo foi aprofundar o conhecimento em relação a atuação do observatório no município santa-mariense, descrevendo experiências e práticas aplicadas, analisando igualmente a metodologia utilizada e as contribuições em relação ao controle social público.

Esse tipo de observação e assunto estudado costuma ser essencialmente não estruturado, enquanto que a observação simples e sistemática costuma ser baseada em estruturas pré-formuladas. Já na observação semiestruturadas, o observador define algumas categorias de observação, porém mantém-se aberto à formação de novas categorias (FERREIRA ET AL., 2012).

Esta técnica possibilita ao pesquisador e aos participantes da pesquisa desenvolverem um relacionamento mútuo de confiança, essência necessária para que os participantes revelem "os bastidores das realidades," assim como as suas experiências particulares, que geralmente são escondidos de estranhos (PATERSON; BOTTORFF; HEWAT, 2003).

A observação permite também a detecção e a obtenção de informações por vezes não apreendidas por outros métodos. Por outro lado, exige rigor e sistematização específicos, diferenciando-se da observação informal e denominando-se observação científica. Para esta última, tem-se um objetivo específico e a questão de pesquisa pode versar sobre os contextos sociais e influência dos mesmos sobre as relações humanas (CANO; SAMPAIO, 2007).

Para construção da presente pesquisa, foi realizada uma análise documental, que são os documentos referentes aos relatórios de prestação de contas quadrimestral do Observatório Social de Santa Maria - OSSM, os quais foram obtidos via site e por meio de envio de e-mail endereçado à presidência do observatório.

No que compete à análise dos dados apresentados na pesquisa, estes foram extraídos a partir da prestação de contas quadrimestral do período de janeiro a agosto de 2019, realizada no mês de setembro do ano de 2019, pela diretoria do OSSM. Em seguida, seguem os resultados com as respectivas análises e discussões.

\section{Análise e Resultados}

\section{O Observatório Social de Santa Maria como instrumento no controle social e sua atuação} no munícipio

O munícipio de Santa Maria (SM) está localizado no Estado do Rio Grande do Sul (RS) e segundo dados do Instituto Brasileiro de Geografia e Estatística (IBGE), apresenta população estimada de 289.123 pessoas, considerada uma cidade de médio porte e de grande influência na 


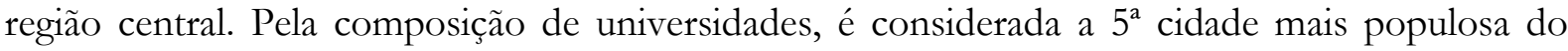
estado e, isoladamente, a maior da região, contendo uma área da unidade territorial em 2018, última atualização do IBGE, de $1.781 .566 \mathrm{~km}^{2}$ (IBGE, 2019)

A renda per capita do munícipio, composta por trabalhadores formais no ano de 2017, foi de 3,2 salários mínimos. E ainda conforme dados do IBGE, o Índice de Desenvolvimento Humano - Santa Maria é 0,784, em 2010, o que situa esse munícipio na faixa de Desenvolvimento Humano Alto (IDHM entre 0,700 e 0,799). A dimensão que mais contribui para o IDHM do munícipio é longevidade, com índice de 0,848, em seguida de Renda, com índice de 0,795, e de Educação, com índice de 0,715 (IBGE, 2019).

O observatório social do município de Santa Maria foi constituído no ano de 2010, a partir da iniciativa de empresários da área contábil do município, que participaram de eventos do OSB em outras cidades e identificaram o potencial de trabalho para SM, município que se tornou protagonista no Estado diante da criação do primeiro observatório.

Apesar de fundado no ano de 2010, e sem registros de atividades documentadas referentes ao período, o OSB-Santa Maria está sob nova diretoria administrativa. No decorrer do ano de 2019 houve a posse da atual administração.

A gestão de 2019/2020 está composta por 17 integrantes. A estrutura está organizada da seguinte forma: Diretoria - Conselho de Administração, com a atual Presidente (1 pessoa) e os vice-presidentes (4 pessoas), compostos e divididos por setores, que são assuntos administrativofinanceiro; assuntos institucionais e de alianças; assuntos de produtos e metodologia; e assuntos de controle social e comunicação. Tem-se, ainda, o setor de conselho fiscal (6 pessoas), composto por titulares e suplentes, e mais os voluntários auxiliares das atividades (6 pessoas).

O observatório adota a prática de firmar parcerias para atingir os objetivos, e buscar apoio para capacitação e angariar mais voluntários, e para isso acontecer, o OSSM conta, basicamente, com o aporte de recursos de mantenedores e com as contribuições dos observatórios que compõem a rede, conforme dados do OSSM disponibiliza, sendo constituído por representantes de empresas e entidades, com instituições de ensino privada do próprio munícipio.

O OSSM atua em forma de associação civil, como pessoa jurídica de direito privado, sem fins lucrativos, tendo ferramenta principal, o monitoramento das contas públicas em nível municipal e a prevenção do desvio dos recursos públicos.

Nos meses de abril e maio ocorreram as fases de planejamento e capacitação dos diretores e dos voluntários, desenvolvendo e aprimorando conhecimento. O Observatório Social do Brasil promove a disseminação de treinamentos com os voluntários através de uma 
plataforma online, para com os OS dos municípios. Ou ainda, os diretores realizam capacitação através de encontros, palestras, reuniões e dentre outros. Desempenhando conhecimento contínuo, com a convicção que é preciso atualizar continuamente as capacitações dos membros dos OSs, por ter uma constante formação de voluntários (OSB, 2019).

A atuação do OSSM é um importante espaço de cidadania e da participação popular, por meio do trabalho voluntariado de representantes de diversas entidades e organizações, auxiliando a administração pública de maneira preventiva e contribuindo para a transparência da gestão, por meio de análises de licitações, compras e contratações de serviços por agentes públicos, acompanhamento das obras públicas.

A metodologia utilizada na atuação do observatório ocorre de forma preventiva no fluxo do processo e antes que os recursos sejam gastos, concentrando na análise de editais de licitação, dispensa de licitação e inexigibilidade. Com a publicação do edital do município, os membros do observatório fazem uma análise com o auxílio de um check-list padrão fornecido pelo OSB. Com o edital, publicado em conformidade com a legislação vigente, é realizada uma pesquisa de empresas no mercado local que ofertem aquele determinado produto ou serviço descrito no processo licitatório, cuja pesquisa serve de parâmetro para comparação com os valores do mercado local e os publicados no edital.

Caso detecte indício de alguma irregularidade no referente edital publicado, é elaborado um ofício pelos voluntários integrantes do observatório do município, com as respectivas dúvidas e questionamentos sobre a irregularidade. Em um primeiro momento, a OS encaminha o ofício elaborado ao responsável do órgão municipal, e aguarda a resposta com a irregularidade corrigida e o edital republicado; se não houver resposta, comunica-se a Câmara Municipal de Vereadores, com um novo oficio relatando o fato e requerendo providências. Caso não se obtenha resposta da Câmara, o observatório reportará o assunto ao Ministério Público, comunicando via ofício os fatos ocorridos, onde aguardará a abertura de procedimentos investigativos.

Há também o acompanhamento na entrega dos serviços ou produtos adquiridos por licitação, medida que se presta para averiguar a conformidade dos termos contidos em edital e no contrato.

Com tais medidas, apreende-se que a atuação do OS contribui para a eficiência e transparência quanto à qualidade na aplicação dos recursos públicos, por meio do exercício da cidadania, na execução orçamentária, aquisição, entrega e utilização de produtos e serviços públicos. A seguir, apresenta-se o Quadro 2, onde pode-se visualizar os procedimentos e as formas de atuação do observatório social e evidenciar o detalhamento da atuação do observatório no município. 
Quadro 2 - Detalhamento da atuação desenvolvido pelo observatório social:

\begin{tabular}{|c|c|}
\hline Contribuição & Ação \\
\hline $\begin{array}{l}\text { Acompanhamento, } \\
\text { fiscalização e } \\
\text { sugestões de } \\
\text { melhorias }\end{array}$ & $\begin{array}{l}\text { As sugestões são entregues para os gestores por meio de ofícios e } \\
\text { também são explanadas nas apresentações quadrimestrais. Também é } \\
\text { realizado um acompanhamento dos políticos via portais, jornais e } \\
\text { mídias sociais. Além disso, é incentivado aos voluntários a } \\
\text { acompanhar o que os políticos estão fazendo. }\end{array}$ \\
\hline $\begin{array}{l}\text { Incentivo na } \\
\text { participação de mais } \\
\text { empresas em } \\
\text { licitações }\end{array}$ & $\begin{array}{l}\text { O incentivo ocorre através de cursos e também na busca contínua de } \\
\text { divulgação das licitações por outros meios de comunicação. }\end{array}$ \\
\hline $\begin{array}{l}\text { Divulgação de atos } \\
\text { públicos }\end{array}$ & $\begin{array}{l}\text { As informações são transmitidas até a população por meio de } \\
\text { palestras e das apresentações quadrimestrais da prestação de contas do } \\
\text { próprio observatório, que é uma exigência a todos os observatórios. } \\
\text { Essa apresentação é realizada pelo observatório, em um evento, } \\
\text { reunião do próprio observatório, para os órgãos públicos e para a } \\
\text { sociedade. }\end{array}$ \\
\hline $\begin{array}{l}\text { Mudança de } \\
\text { percepção do gestor } \\
\text { público e da } \\
\text { população com o } \\
\text { trabalho dos } \\
\text { observatórios }\end{array}$ & $\begin{array}{l}\text { A percepção identificada é a grande curiosidade do que o observatório } \\
\text { está fazendo ou pesquisando quando está presente em uma licitação. } \\
\text { O observatório é atendido pelos órgãos públicos, como prevê a } \\
\text { legislação. }\end{array}$ \\
\hline $\begin{array}{l}\text { Monitoramento de } \\
\text { licitações e gastos } \\
\text { públicos }\end{array}$ & $\begin{array}{l}\text { O acompanhamento se inicia quando é publicado o edital nos portais } \\
\text { da Transparência dos órgãos públicos, os voluntários do Observatório } \\
\text { realizam um checklist e verificam o processo físico no órgão público. } \\
\text { Este checklist é desenvolvido pelo observatório para analisar se os } \\
\text { certames estão cumprindo com o que foi designado no edital. Após o } \\
\text { certame os voluntários participam da entrega dos produtos e } \\
\text { confirmam o pagamento no portal da transparência. Em alguns editais } \\
\text { é realizado um aprofundamento da pesquisa. Infelizmente não é } \\
\text { realizado o acompanhamento de todas as licitações que são realizadas } \\
\text { por falta de voluntários. Neste observatório é realizada, atualmente, a } \\
\text { escolha aleatória das licitações para participar das aberturas e em } \\
\text { algumas delas é acompanhado a entrega dos produtos. }\end{array}$ \\
\hline $\begin{array}{l}\text { Prevenção de atos } \\
\text { inidôneos }\end{array}$ & $\begin{array}{l}\text { Caso é encontrado algo inapropriado o primeiro procedimento é } \\
\text { entrar em contato com o gestor público. Se houver retorno } \\
\text { satisfatório é cumprida a missão dos Observatórios (refeito a licitação } \\
\text { ou até o observatório ter argumentos que está sendo feito correto). } \\
\text { Mas se não houver retorno, o processo é informar aos órgãos } \\
\text { públicos, tais como o Ministério Público Federal, Câmara de } \\
\text { Vereadores e o tribunal de Contas da União, para que eles tomem suas } \\
\text { providências. Além de informar a sociedade nas apresentações } \\
\text { quadrimestrais. Mesmo sem encontrar indícios de irregularidade não } \\
\text { significa que não possa haver problemas ou que o processo não possa } \\
\text { ser melhorado. }\end{array}$ \\
\hline
\end{tabular}

Fonte: Adaptado de ZANETTI, BONZANINI (2018).

Com o detalhamento explanado no Quadro 2, além do acompanhamento da forma de atuação do observatório, faz-se uma comparação entre o que é almejado e o que é alcançado, demonstrando as atuações, os desafios e as dificuldades enfrentadas para o desempenho do 
trabalho. Constata-se ainda, que o observatório pretende aprimorar a forma de trabalho e ampliar as ações, por meio de incentivo da participação da população, objetivando, deste modo, ampliar as ações de acompanhamento na fiscalização das contas públicas. Além disso, há o intento de incentivo voltado às micro e pequenas empresas, pela via das capacitações feitas pelo observatório, a concorrer as licitações municipais, e, desta maneira, começa-se a lançar uma mudança na percepção do ente público e da população, com o trabalho desempenhado pela entidade social, que prima incessantemente pela prevenção e erradicação de atos ilícitos na gestão pública.

Conclui-se, assim, que é de grande relevância o trabalho realizado pelo Observatório Social, tendo como viés a contribuição na transparência dos atos públicos, como o controle social, e a gestão fiscal, por sua vez, apresenta-se como uma das formas de contribuição para monitoramento das licitações em tempo real e dos gastos públicos, através de apontamentos e cobranças por melhorias na qualidade da aplicação dos recursos públicos, bem como na divulgação dessas ações para o conhecimento da população. Como resultado dessas ações, obtém-se a economia dos recursos e, consequentemente, a inibição de atos ilícitos praticados pelo poder público.

Afora essas ações, tem-se também a formação de parcerias com instituições de ensino, que corrobora para a disseminação da educação fiscal para a população, sensibilizando e conscientizando a sociedade sobre a responsabilidade e o dever de observação e monitoramento do uso adequado do dinheiro público, tudo isso sucedendo concomitantemente ao incentivo da participação das micro e pequenas empresas nas licitações, fomentando a concorrência e a economia do próprio munícipio.

\section{Resultados obtidos com a intervenção do Observatório Social do Munícipio}

$\mathrm{Na}$ atual gestão tem-se a assessoria de comunicação como instância que estabelece entre a entidade, o público externo e a população em geral, canais públicos de interlocução, mediante o uso de rede social própria de fácil acesso a todos, para a divulgação do desenvolvimento dos programas realizados, como palestras, cursos, seminários, prática que contribui para a difusão do conhecimento com a sociedade e explana a contribuição do OS para com o município.

O OS no município santa-mariense preza pela realização de cursos de qualificação desenvolvidos com o auxílio de professores e profissionais de áreas afins, envolvendo variados temas em cada módulo, como mais adiante detalhar-se-á. Um dos principais objetivos do observatório é disseminar informações e incentivar a participação da população do munícipio na 
ação fiscalizatória do investimento dos recursos públicos. Para tanto, os cursos de capacitação mostram-se como uma fermenta importante na formação de cidadãos conscientes; no OS de Santa Maria os cursos vêm ocorrendo desde o mês de junho/2019, que conta com parceria firmada com uma instituição de ensino do município, que disponibilizou seu espaço físico para as devidas capacitações do observatório (OSSM, 2019).

Conforme divulgado na página da rede social do observatório, o primeiro projeto foi voltado à educação, com a consumação do Projeto 'Cidadania e Transparência Pública', realizado em parceria com a instituição de ensino, cujo módulo foi ministrado mediante oferta de palestras no ano de 2019, que abordaram os seguintes temas: I - Capacitação OSSM; II - Capacitação em Transparência Pública - O OSSM e o Papel do Cidadão; III - Capacitação em Transparência Pública - Lei de Acesso à Informação; Lei dos Serviços Públicos; Ouvidoria Municipal; IV Capacitação em Transparência Pública - Licitações; e o módulo V - Capacitação em Transparência Pública - Competências dos Poderes Executivo e Legislativo (OSSM, 2019).

O OSSM realiza palestras com o intuito de sensibilizar as pessoas para o exercício social da cidadania e convidar para atuarem como voluntários no OSSM. Assim, fomenta-se a formação e captação de novos voluntários, com treinamento constante dos membros, com incentivo na sustentabilidade e no fortalecimento das parcerias engajadas, com produção e publicação dos relatórios quadrimestrais da atuação, com realização de ações de planejamento e de avaliação do andamento da entidade a cada quatro meses, além do cumprimento das normas estabelecidas no código de conduta e da atualização constante no canal de comunicação com a sociedade.

A equipe de voluntários do OSSM realiza reuniões às quartas-feiras à noite, momento em que debatem coletivamente sobre as atividades já desempenhadas e, igualmente, planejam as atividades a serem exercidas posteriormente, sendo esta também a oportunidade que os voluntários apresentam e escolhem os editais de licitações da Prefeitura para trabalharem. Nesses encontros, os voluntários detalham como está o andamento das atividades escolhidas anteriormente, bem como solicitam o auxílio ou esclarecimento sobre alguma dificuldade que estejam enfrentando na execução das atividades.

Para tanto, a equipe de voluntários do OSSM conta com a troca de conhecimento e experiência dos voluntários, e, além disso, as dificuldades enfrentadas podem ser objeto de consulta formal à Prefeitura. Nestes encontros, são explanados o andamento dos pedidos de informação elaborados anteriormente pelo grupo e encaminhados pelo OSSM à Prefeitura ou à Câmara.

O OSSM, na atual gestão, realizou a primeira prestação de contas, referente ao período de janeiro a agosto do ano de 2019 - apresentada no dia 16 de setembro de 2019, em Santa 
Maria, durante uma reunião-almoço do Fórum das Entidades Empresariais de Santa Maria e da diretoria do OSSM, ocasião em que foram explanadas as atividades referentes à atuação no monitoramento das licitações públicas municipais, como meio utilizado para melhorar os processos e gerar economia ao munícipio, que muitas vezes resulta no encaminhamento de ofícios ao setor de licitações da Prefeitura, com pedidos de esclarecimentos e com envio de sugestões (OSSM, 2019).

O 'Quadro 3' a seguir exibe prestação de contas quadrimestral da gestão 2019/2020 da entidade OSSM, referente ao período de janeiro a agosto de 2019, em que se verifica que o OS obteve uma receita de $\mathrm{R} \$ 11.019,33$ (100\%), da qual $\mathrm{R} \$ 3.600,00$ (32,67\%) são oriundas de doações de pessoas físicas.

Quadro 3 - Síntese dos relatórios quadrimestrais de janeiro a agosto de 2019.

\begin{tabular}{|l|c|c|}
\hline \multicolumn{1}{|c|}{ Meses } & Acumulado & S/REC \\
\cline { 2 - 3 } & $\mathbf{2 0 1 9}$ & $\mathbf{\%}$ \\
\hline RECEITA BRUTA & $\mathbf{1 1 . 0 1 9 , 3 3}$ & $\mathbf{1 0 0 \%}$ \\
\hline Doações de Pessoas Físicas & $3.600,00$ & $32,67 \%$ \\
\hline Doações de Pessoas Jurídicas & $7.419,33$ & $67,33 \%$ \\
\hline RECEITA LÍQUIDA & $\mathbf{1 1 . 0 1 9 , 3 3}$ & $\mathbf{1 0 0 , 0 0 \%}$ \\
\hline $\begin{array}{l}\text { DESPESAS } \\
\text { OPERACIONAIS }\end{array}$ & $\mathbf{( 8 . 9 3 9 , 1 2 )}$ & $\mathbf{- 8 1 , 1 2 \%}$ \\
\hline \multicolumn{1}{|c|}{ Meses } & $\mathbf{A c u m u l a d o}$ & $\mathbf{S / R E C}$ \\
\cline { 2 - 4 } & $\mathbf{2 0 1 9}$ & $\mathbf{0}$ \\
\hline RESULTADO & $\mathbf{8 , 1 6}$ & $\mathbf{0 , 0 7 \%}$ \\
\hline FINANCEIRO & $(496,81)$ & $-4,51 \%$ \\
\hline Despesas Financeiras & 504,97 & $4,58 \%$ \\
\hline Receitas Financeiras & $\mathbf{2 . 0 8 8 , 3 7}$ & $\mathbf{1 8 , 9 5 \%}$ \\
\hline $\begin{array}{l}\text { RESULTADO } \\
\text { PERÍODO }\end{array}$ & & \\
\hline
\end{tabular}

Fonte: Dados da pesquisa (OSSM, 2019)

Conforme disposto no Quadro 3, tem-se como a segunda maior fonte de recursos no ano as doações de pessoas jurídica, no montante de $\mathrm{R} \$ 7.419,33$ (67,33\%). Por outro lado, no mesmo período o OSSM acumulou despesas de ordem operacional de $\mathrm{R} \$ 8.939,12(-81,12 \%)$, despesas financeiras de $\mathrm{R} \$ 496,81$ (-4,51\%) e obteve em receitas financeiras o valor de $\mathrm{R} \$ 504,97$ (4,58\%), resultando um superávit contábil de $\mathrm{R} \$ 2.088,37$ (18,95\%) no período (OSSM, 2019).

Examinando-se a prestação de contas do observatório do município constante no Quadro 3, verifica-se que nos primeiros meses de atuação, o observatório trabalhou também em 
angariar doações de pessoas físicas e jurídicas para custear as despesas operacionais, assim como detectou-se a existência de vínculo com conta bancária, ato que gerou tanto despesa, como receita financeira, cujo resultado foi de um superávit no importe de $\mathrm{R} \$ 2.088,37$, auferido no final do $2^{\circ}$ quadrimestre do ano de 2019.

Neste período foram monitoradas dez licitações, com ofícios enviados ao setor de licitações da Prefeitura do munícipio, conforme explanado na prestação de contas. O OSSM contribuiu para o cancelamento de dois contratos de registro de preços abusivos, gerando uma economia prevista de $\mathrm{R} \$ 54$ mil. Houve também o cancelamento de uma licitação para compra de antivírus para o Executivo e outra para o Legislativo, também motivadas por preço abusivo, direcionamento de fornecedor e falta de competividade, na modalidade de licitação pregão presencial.

Nestes dois últimos casos, a economia possível, pelo valor de mercado, foi de $\mathrm{R} \$ 201$ mil/ano e R $\$ 68,3$ mil/ano, respectivamente. Portanto, o trabalho do observatório, em parceria com a Prefeitura, resultou numa economia aproximada de $\mathrm{R} \$ 323.300,00$ ano (OSSM, 2019).

Ressalta-se que tal economia não reflete na totalização de licitações da cidade de Santa Maria no decorrente ano vigente. A constatação de licitações monitoradas é pequena, em virtude, principalmente, do reduzido número de voluntários existentes, porém os dados possibilitam analisar o resultado do trabalho dos voluntários e do potencial de colaboração que os O.S podem gerar à sociedade.

A atual gestão do observatório obteve reconhecimento por meio de premiação, como continuidade do Projeto Obra Transparente, alcançando o $2^{\circ}$ lugar na categoria "Responsabilidade Social”, título concedido pela Associação Nacional dos Procuradores da República (OSSM, 2019).

Conforme dados extraídos do OS do munícipio, somente $9 \%$ das micro e pequenas empresas do munícipio estão habilitadas a participarem de licitações, e para mudar este contexto, o observatório vem realizando reuniões com o Sebrae com o objetivo de formatar um curso de Licitações para a capacitação de servidores públicos e de micro e pequenas empresas, para que possam concorrer às licitações municipais. Com tal iniciativa, almeja-se ampliar a concorrência nas licitações, garantido que os recursos financeiros advindos das licitações permaneçam em Santa Maria, possibilitando também a ampliação de vagas de empregos à população (OSSM, 2019).

Quanto aos desafios, o OSSM destaca para o próximo período (ano 2020), que é o período de mandato da atual gestão, a inclusão de vários obstáculos, dentre eles a sustentabilidade, com necessidade de capacitação de novos colaboradores e parceiros 
independentes, e também a imprescindibilidade de ampliação do número de voluntários, para que haja multiplicação dos grupos de trabalho (OSSM, 2019).

Com os resultados das ações, constatou-se que o observatório social do munícipio vem desempenhando na atual gestão o controle social versus a gestão pública, carecendo, entretanto, de ampliação da participação da sociedade santa-mariense, mediante voluntariado, cujo resultado certamente redundará na promoção e na ampliação do espaço democrático para o cidadão, que pode participar, monitorar e questionar a forma que o poder público utiliza os recursos financeiros, por meio de uma entidade que utiliza a democracia representativa para se organizar internamente, visando atingir os objetivos propostos, com a participação conjunta da sociedade.

Além disso, o observatório social do munícipio ainda incentiva a ampliação da concorrência em licitações públicas, institui parcerias com faculdades e entidades da sociedade, para obter apoio institucional, fortalece a representatividade, busca profissionais especializados para disseminar capacitação aos voluntários e conquista mais pessoas dispostas em atuar como voluntário.

No que tange à representatividade e importância das ações do observatório no município, constata-se a consolidação paulatina da democracia participativa, por meio do controle social na interferência de políticas públicas, do esclarecimento na prestação de contas e da transparência dos atos do governo para com a sociedade. O observatório além de monitorar as ações do ente público, visa também garantir, em especial, a confiabilidade das informações que são disponibilizadas para a população, trazendo, assim, mudanças e mais responsabilidades para os órgãos públicos em relação ao controle interno, os quais são os responsáveis pela geração, gestão e compartilhamento de muitas informações.

Por fim, ressalta-se a necessidade de fortalecer os esforços entre a população e as entidades perante o poder público, para garantir qualidade constante no controle social com a cidadania e no processo de ampliação da transparência pública, não somente quantitativa, mas principalmente, qualitativa, visando assegurar a confiabilidade das informações.

\section{Considerações Finais}

Com a realização do estudo, verificou-se que os OSB desempenham um trabalho com eficácia no controle social, com engajamento da sociedade civil do município que resulta no trabalho social relevante e promissor. Com tal medida, auxilia-se o combate à corrupção e as dificuldades de controle da gestão pública, duas deficiências que minimizam o desenvolvimento econômico, político e social de uma determinada região. 
O OS, portanto, em sua essência, busca incessantemente a justiça social contínua, possibilitando o exercício da cidadania.

$\mathrm{Na}$ presente pesquisa analisou-se a atuação da gestão da OS do município de Santa Maria, com a finalidade de conhecer as etapas realizadas pelo OSSM e as dificuldades enfrentadas pela equipe de voluntários. Como obstáculo, o estudo evidenciou a existência de limitações na iniciativa de participação dos cidadãos como voluntários, mas este fato muda à medida que a população vai se conscientizando acerca da importância da democracia participativa e da democracia representativa, com percepção de que os integrantes podem garantir a sustentabilidade da atuação do ente público e gerar responsabilidade dos gestores incumbidos pela administração pública, propiciando, desta forma, o fomento do controle social para a cidadania e determinando a promoção da transparência nas contas públicas.

Observou-se que o OSSM atua no acompanhamento das publicações dos editais das licitações, em tempo real, além de propiciar cursos gratuitos para capacitação de seus membros, ou até mesmo captação de futuros novos membros, mas com foco de disseminar conhecimento à sociedade e monitorar os recursos e gastos públicos com relação à atuação dos gestores públicos.

A prestação de contas do OS é feita a cada quadrimestre, com apresentação dos resultados alcançados e as devidas ações tomadas para a sociedade, por meio de reuniões públicas. No que tange à atuação em atividades com o foco na prevenção, a contribuição do trabalho do observatório proporciona uma economia em valores bem expressivos, embora não se tenha sempre a dimensão exata do alcance ou da economia que este proporciona, porém é notória a importância da gestão dos recursos públicos, mediante controle coletivo social que evita abusos, porquanto existem restrições e dificuldades financeiras nos recursos públicos do município, relacionados, em especial, a carência de recursos humanos e financeiros.

Com o intuito de responder o questionamento principal que objetivou esta pesquisa, constata-se que a atuação do OSSM no município de Santa Maria tem resultados positivos e promissores junto à administração pública. Verificou-se também a existência de parcerias com instituições de ensino, objetivando a eficácia no âmbito do controle social, com o auxílio de palestras ministradas em módulos, voltadas à capacitação da população, cujos conteúdos abordam temas sobre a importância da cidadania social e da transparência pública.

A pesquisa averiguou que, nestes oito meses iniciais da atual gestão do observatório, realizando um trabalho conjunto à Prefeitura do município, com monitoramento em algumas licitações, ocorreu uma economia aproximada de $\mathrm{R} \$ 323.300,00$ de recursos públicos.

Tendo em vista o caráter exploratório e também à própria natureza da pesquisa científica, o assunto aqui abordado não se esgotou e pode servir de base para novos estudos, seja 
em razão da amplitude do tema que exige novas leituras e estudos, ou até mesmo em razão das limitações enfrentadas. A pesquisa se presta também como estímulo e esclarecimento à população acerca da importância dos observatórios sociais para a sociedade, provando que a participação popular está diretamente relacionada ao controle da corrupção, e os observatórios sociais, por sua vez, são disseminadores do controle social no Poder Público.

\section{Referências}

ALVES, M. D. Transparência e Controle Social no Acompanhamento da Aplicação de Recursos Públicos: Atuação do Observatório Social (OS). Brasília, 2015.

ASSIS, M. M. A.; VILLA, T. C. S. O controle social e a democratização da informação: um processo em construção. Revista Latino-Americana de Enfermagem, Ribeirão Preto, v.11, n.3, p.376-382, 2003.

AVRITZER, Leonardo. Instituições participativas e desenho institucional: algumas considerações sobre a variação da participação no Brasil democrático. Opinião pública, v. 14, n. 1, p. 43-64, 2008.

BEHN, R.D. O novo paradigma da gestão pública e a busca da accountability democrática. Revista do serviço Público. V. 49, n.4,: p. 5-45, out./dez.1988.

BEUREN, L. Maria. Como elaborar trabalhos monográficos em contabilidade: teoria pratica. 3. Ed. São Paulo: Atlas, 2008.

BRASIL, CONSTITUIÇÃO. Constituição da República do Brasil. Brasília: Senado Federal, 1988.

BRASIL. Lei Complementar no 101, de 04 de Maio de 2000. Estabelece normas de finanças públicas voltadas para a responsabilidade na gestão fiscal e dá outras providências. Brasília: Senado Federal.

CANO, Débora Staub; SAMPAIO, Izabela Tissot Antunes. O método de observação na psicologia: considerações sobre a produção científica. Interação em Psicologia, v. 11, n. 2, 2007.

CERVO, Amado Luiz; BERVIAN, Pedro Alcino; SILVA, Roberto da. Metodologia Científica. 6. ed. São Paulo: Pearson Prentice Hall, 2007.

COLLIS, J.; HUSSEY, R. Pesquisa em Administração: um guia prático para alunos de graduação e pós-graduação. 2.ed. Porto Alegre: Bookman, 2005.

DOIN, Guilherme Augusto et al. Mobilização social e coprodução do controle: o que sinalizam os processos de construção da Lei da Ficha Limpa e da Rede Observatório Social do Brasil de Controle Social. Pensamento \& Realidade, v. 27, n. 2, p. 56-79, 2012.

FERREIRA, Luciene Braz; TORRECILHA, Nara; MACHADO, Samara Haddad Simões. A técnica de observação em estudos de administração. Encontro da ANPAD, v. 36, p. 1-15, 2012. 
FIGUEIREDO, V. da S.; DOS SANTOS, W. J. L. Transparência e controle social na administração pública. Temas de Administração Pública, v. 8, n. 1, 2013.

GIL, Antônio Carlos. Como elaborar projetos de pesquisa. 6 ed. São Paulo: Atlas, 2017.

GOHN, Maria da Glória. Movimentos Sociais e Educação. 8ª Edição. 2010.

Instituto Brasileiro de Geografia e Estatística - IBGE. Disponível em:

https://cidades.ibge.gov.br/brasil/rs/santa-maria/panorama Acesso em 02/09/2019.

KLEBA, Maria Elisabeth; WENDAUSEN, Agueda. Empoderamento: processo de fortalecimento dos sujeitos nos espaços de participação social e democratização política. Saúde e sociedade, v. 18, p. 733-743, 2009.

MILANI, Carlos RS. O princípio da participação social na gestão de políticas públicas locais: uma análise de experiências latino-americanas e europeias. Revista de Administração Pública, v. 42, n. 3, p. 551-579, 2008.

OBSERVATÓRIO SOCIAL DO BRASIL, O que é um Observatório Social do Brasil, no Munícipio de Santa Maria (OSB)? Disponível em:

http://observatoriosocialdesantamaria.blogspot.com/p/o-que-e_12.html Acesso em 02/07/2019.

O que é um Observatório Social do Brasil (OSB)? Disponível em:

$<$ http://osbrasil.org.br/o-que-e-um-observatorio-social-os/> Acesso em 02/07/2019.

O que é um Observatório Social do Brasil (OSB)? Disponível em:

http://osbrasil.org.br/o-que-e-o-observatorio-social-do-brasil-osb/ Acesso em 02/07/2019.

Oficializado em Santa Maria o primeiro Observatório Social do RS. OAB/RS.

Disponível em:

http://www.oabrs.org.br/noticia-6869-oficializado-em-santa-maria-primeiro-observatorio-socialdo-rs ano de 2010. Acesso em 02/07/2019.

PATERSON, B. L.; BOTTORFF, J. L.; HEWAT, R. Blending observational methods: possibilities, strategies and challenges. International Journal of Qualitative Methods, v. 2, n. 1, p. 29-38, 2003.

QUEIROZ, Lécia Dias de. Observatório Social do Brasil: Instrumentos de Controle Social da Gestão Pública. Universidade Federal de Uberlândia Faculdade de Gestão e Negócios Mestrado Profissional em Gestão Organizacional, 2017.

SILVA, Dionísio de Souza Nascimento. Controladoria na Administração Pública sob a ótica do controle social: O caso do Observatório Social do Brasil. UFRGS Escola de Administração Programa Pós-Graduação em Administração. POA, 2017.

SOUZA, Dny Sandra da Silva. Transparência Pública: Analise dos instrumentos de transparência e controle social no município de Cocoal-Ro. Fundação Universidade Federal de Rondônia Campus Professor Francisco Gonçalves Quiles Departamento Acadêmico de Ciências Contábeis, 2018. 
TENÓRIO, Fernando G. A trajetória do programa de estudos em gestão social (PEGS). Revista de Administração Pública, v. 40, n. 6, p. 1145-1162, 2006.

VIEIRA, Rejane Esther. Administração pública de caráter democrático e participativo no Estado de Direito no Brasil: o Novo Serviço Público face à Constituição de 1998. Revista Direitos Fundamentais e Democracia, v. 4, Curitiba, PR, 2008.

ZANETTI, J.; BONZANINI, O.A. Transparência e Controle Social na Gestão Pública: Atuação e Contribuições dos Observatórios Sociais no Brasil. Universidade Regional Integrada do Alto Uruguai e das Missões - URI, 2018. 